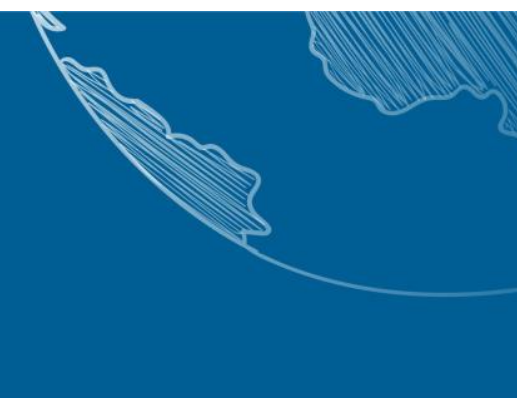

\title{
GÊNERO NA EDUCAÇÃO INFANTIL: (DES)CAMINHOS DE UMA POLÍTICA PÚBLICA NÃO CONSOLIDADA
}

\author{
GENDER IN CHILDHOOD EDUCATION: THE WAY (OR THE MISPLACE) OF A \\ NON-CONSOLIDATED PUBLIC POLICY
}

\author{
GÉNERO EN LA EDUCACIÓN INFANTIL: (DES)CAMINOS DE UNA POLÍTICA \\ PÚBLICA NO CONSOLIDADA
}

\author{
Daniela Auad ${ }^{1}$ Maria Rita Neves Ramos ${ }^{2}$
}

\begin{abstract}
RESUMO
O presente artigo é resultado de pesquisa cujo foco principal foi conhecer como a Educação Infantil lida com as relações de gênero no município de Juiz de Fora, no Estado de Minas Gerais. Com esse propósito, o estudo contou com procedimentos metodológicos combinados, na forma de buscas bibliográficas, documentais e também entrevistas com professoras da rede, representantes da Secretaria de Educação e mulheres integrantes da equipe da Coordenadoria de Políticas Públicas Casa da Mulher. O debate desses dados, com referenciais feministas e com a atual conjuntura política, é rico pois o momento aponta para a retirada do tema gênero dos Planos Nacionais e Municipais de Educação, ao lado da forma historicamente ausente ou precária com a qual a rede de ensino aborda a questão. Todo esse contexto pode significar descompasso entre os anseios democráticos e a Educação das crianças pequenas, uma vez que a censura de discussões junto às crianças rompe completamente com as prerrogativas constitucionais que reconhecem a criança como cidadã. Tal cenário se traduz em mais um desafio para as políticas voltadas à criança. Esta torna a ser, de maneira ultrapassada, vista como incapaz de lidar com debates voltados à sua própria realidade social e ao cotidiano de outras pessoas com as quais convive. Assim sendo, se colocam em xeque tanto os posicionamentos políticos referentes às variadas concepções de infância presentes na formação inicial e continuada de professores/as quanto o reconhecimento social que as múltiplas infâncias têm nas variadas searas da sociedade brasileira.
\end{abstract}

PALAVRAS-CHAVE: Gênero; Educação; Educação Infantil; Políticas públicas; Feminismos.

\begin{abstract}
This work brings to some considerations data obtained in research of Master's degree, whose principal focus was knowing how childhood education handles with gender relations in the municipality of Juiz de Fora (MG). With this purpose, the study counted with bibliographical researches, documental and also interviews with teachers of network, representatives of Education Secretary and Coordination of the
\end{abstract}

\footnotetext{
${ }^{1}$ Actualmente, es Profesora del Programa de PósGrado en educación de la Facultad de Educación de la Universidad Federal de Juiz de Fora (PPGE/FACED/UFJF). Líder del Colectivo Feminista Flores Raras y del Grupo de Estudios y Investigaciones Educación, Comunicación y Feminismos (UFJF). Pós- Doctora en Sociologia por la UNICAMP (Universidad Estadual de Campinas), Pedagoga, Maestra y Doctora por la Facultad de Educación de la USP (Universidad de São Paulo), en el área de concentración Sociologia de la Educacióno. Contcato: auad.daniela@gmail.com

${ }^{2}$ Pedagoga; Doctoranda en Educación por la Universidad Federal de Juiz de Fora; Maestra y Especialista en Educación por la misma institución. Integrante del Colectivo Feminista Flores Raras y del Grupo de Estudios y Investigaciones Educación, Comunicación y Feminismos (UFJF). Contacto: nevesramosm@yahoo.com.br
}

\begin{tabular}{l|l|l|l|}
\hline Rev. Ciências Humanas & Frederico Westphalen, RS & Vol. 19 n. 01 & Jan./abr. 2018 \\
\hline
\end{tabular}

\begin{tabular}{l|l|l} 
Recebido em: 13/08/2017 & Aceito em: 21/05/2018 & Pg. 77 - 94
\end{tabular}




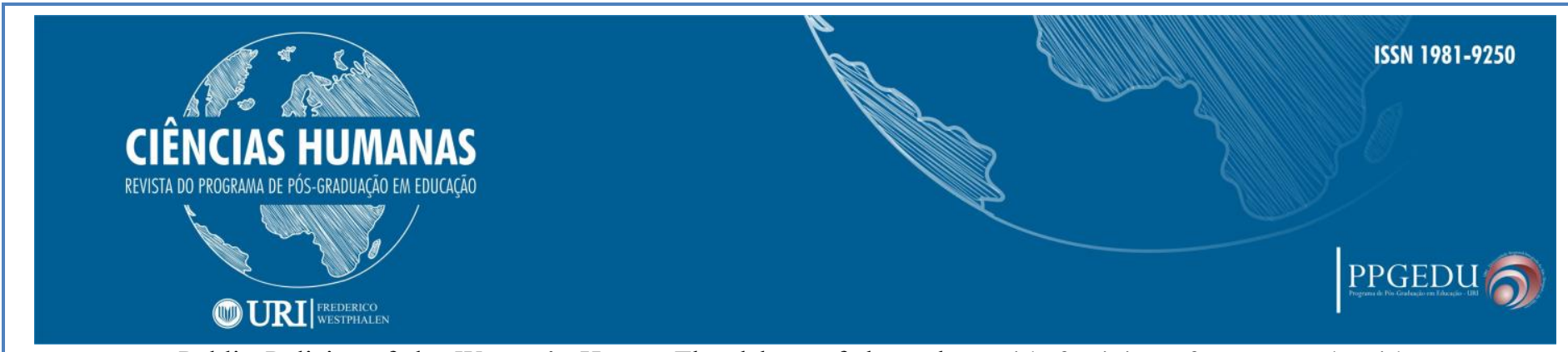

Public Policies of the Women's House. The debate of these data with feminist references and, with current political situation is rich, once the moment points out the removal of gender theme from the National and Municipal Plans of Education, together with the historically absent and precarious way which the teaching network addresses the question. All this context could mean an unbalance between democratic desires and the education of small children, since the censure on the discussions along with the children completely breakout with constitutional prerogatives that recognize the child as a citizen. Such scenario can be translated as another challenge for policies toward children. The formers are viewed once more, in an old fashionable way, as unable to handle with debates on their own social reality and the other people with whom they live together. Therefore, we can put in check both the political positions regarding to the various conceptions of childhood present in the initial and continuous teachers training and the social acknowledgment that multiples childhoods have in the various fields of Brazilian society.

KEYWORDS: Gender; Education; Childhood Education; Publics policies; Feminisms.

\section{RESUMEN}

El presente artículo es resultado de investigación cuyo foco principal fue conocer como la Educación Infantil lidia con las relaciones de género en el municipio de Juiz de Fora, en el Estado de Minas Gerais. Con ese propósito, el estudio contó con procedimientos metodológicos combinados, en la forma de búsquedas bibliográficas, documentales y también entrevistas con maestras de la red, representantes de la Secretaria de Educación y mujeres integrantes del equipo de la Coordinadora de Políticas Públicas Casa de la Mujer. El debate de eses datos, con referenciales feministas y con la actual coyuntura política, es rico pues el momento apunta para la retirada del tema género de los Planes Nacionales y Municipales de Educación, al lado de la forma históricamente ausente o precaria con la cual la red de enseño aborda la cuestión. Todo ese contexto puede significar descompaso entre los anhelos democráticos y la Educación de los niños pequeños, una vez que la censura de discusión junto a los niños rompe completamente con las prerrogativas constitucionales que reconocen al niño como ciudadano. Tal escenario se traduce en más un desafío para las políticas vueltas al niño. Este vuelve, de manera ultrapasada, a ser visto como incapaz de lidiar con debates vueltos a su propia realidad social y al cotidiano de otras personas con las cuales convive. Así siendo, se ponen en jaque tanto los posicionamientos políticos referentes a las variadas concepciones de infancia presentes en la formación inicial y continuada de maestro/as como el reconocimiento social que las múltiples infancias tienen en los variados campos de la sociedad brasileña.

PALABRAS CLAVE: Género; Educación; Educación Infantil; Políticas públicas; Feminismos.

\section{INTRODUÇÃO}

Ao considerar a pesquisa ter sido realizada em um município de $600 \mathrm{mil}$ habitantes no Estado de Minas Gerais, há de se relembrar dos escritos de Cláudia Fonseca, quando a pesquisadora ressalta, em estudo etnográfico, "quando cada caso não é um caso" (1999). O presente artigo apresenta elementos que podem ser - e geralmente são - encontrados em sistemas de ensino de variados municípios de Estados em todo o território nacional e até mesmo em outros países, conforme bibliografia analisada sobre Educação Infantil e Relações de Gênero, que será tematizada adiante, no presente artigo.

\begin{tabular}{|c|c|c|c|}
\hline Rev. Ciências Humanas & Frederico Westphalen, RS & Vol. 19 n. 01 & Jan./abr. 2018 \\
\hline Recebido em: 13/08/2017 & \begin{tabular}{l|l}
7 & Aceito em: $21 / 05 / 2018$
\end{tabular} & & Pg. $77-94$ \\
\hline
\end{tabular}




\section{CIÊNCIAS HUMANAS}

REVISTA DO PROGRAMA DE PÓS-GRADUAĞ̈O EM EDUCAĞ̄o

\section{(1) URI|}

Dito isto, cabe ressaltar que a pesquisa que deu origem à esse artigo realizou um mapeamento de aspectos que compusessem minimamente a discussão do tema gênero junto à Educação Infantil no município de Juiz de Fora (MG). O estudo revela uma série de descontinuidades e controvérsias políticas que atravessam os fazeres pedagógicos junto às crianças pequenas e que continuam sendo objeto de calorosos debates entre a sociedade civil, professoras/es e as orientações dos Planos Nacionais e Municipais de Educação em todo o Brasil. Para elucidar essa afirmação, o presente trabalho debate a atuação de relações conservadoras que dispensam tratamentos desiguais às pessoas, desde as interações sociais e profissionais que subalternizam as mulheres em suas carreiras, passando pela pauta educacional, que vem desrespeitando e restringindo o debate sobre desigualdade de gênero. Tal assertiva se delineia a partir de dados obtidos em pesquisa, no decorrer dos anos de 2014 e 2015, por meio de coleta bibliográfica, análise de documentos e entrevistas com professoras da rede municipal de Juiz de Fora (MG), técnicas do setor da Educação Infantil da Secretaria de Educação e representante da Casa da Mulher, importante órgão de defesa das mulheres vítimas de violência.

A pesquisa realizada em Minas Gerais ainda lança mão de inspiração etnográfica. E, nesse sentido, o termo inspiração é apropriado a partir de autoras como a já citada Cláudia Fonseca (1999), que ao retomar as teorizações antropológicas e sociológicas sobre o método etnográfico, bastante difundido nas Ciências Sociais, pondera sobre as profícuas possibilidades da utilização dessa abordagem metodológica no campo da Educação. Se por um lado há discussões sobre o tempo de observação e a profundidade da imersão do/a pesquisador/a em contexto analisado, bem como os atravessamentos e aplicações que as interpretações dos dados ganham em pesquisas, por outro, a autora ressalta que a área comunicativa estabelecida entre as pessoas pode abrir caminhos singulares de investigação, pois o/a pesquisador/a vem a se afastar de teorizações e métodos abstratos que carregam em si a ideia de homogeneidade e generalidade dos sistemas sociais. Nessa perspectiva, a leitura dos particularismos contribuem com o "[...] o dado particular que abre o caminho para interpretações abrangentes" (FONSECA, 1999). Em outras palavras, é possível acessar as acepções globais por meio das interações com o local. Assim, embora o campo de pesquisa tenha 


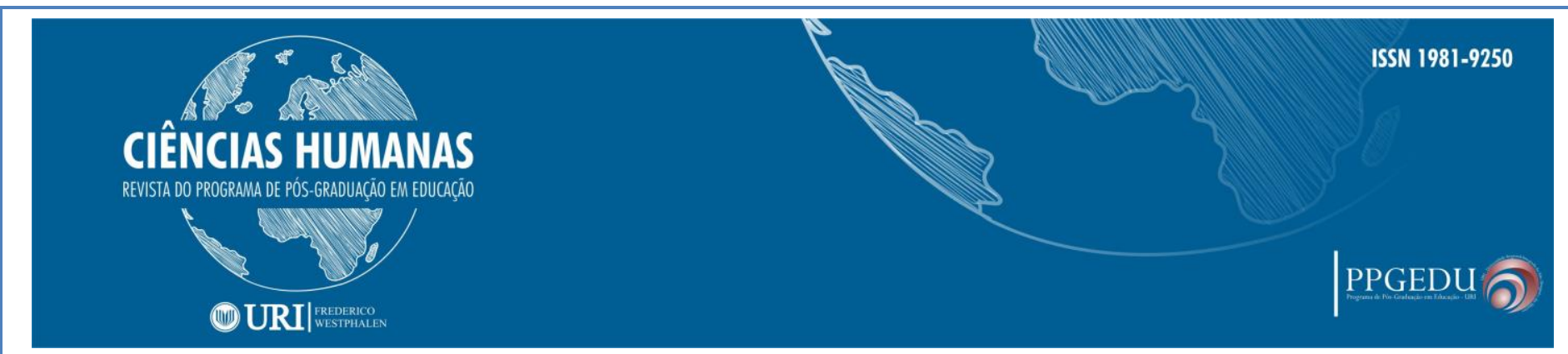

buscado conhecer as discussões sobre as relações de gênero no âmbito da Educação Infantil em município mineiro, tal discussão não se restringe apenas à essa localidade, mesmo porque tem-se notícia de embates recentes sobre a abordagem do tema gênero em todos os níveis da Educação também em outros Estados da Federação. Acrescentamos a isso o reconhecimento da Educação Infantil como seara de acúmulo e desenvolvimento de pesquisa, com especial apreço para os esforços de pesquisadoras feministas que se debruçam em análises sobre as relações de gênero e o mundo infantil desde a década de 1970. As contribuições dessas estudiosas contrariam eventuais afirmações sobre a falta de acúmulo sobre Educação Infantil e Gênero e são evocadas nesse trabalho pois concorrem para a existência de uma "[...] pedagogia da educação infantil que se funda no espaço e no tempo que constrói a condição infantil na esfera pública" (FARIA, 2006, p.282).

A partir dessa conjuntura, o presente texto lança mão dos achados de pesquisa com a pretensão de apresentar olhares possíveis sobre o complexo educacional que se revela quando a pauta é a abordagem da categoria gênero junto às crianças, questão notadamente perpassada por um panorama político mais amplo do que se supõe. Nesse recorte de pesquisa, a visibilidade - ou a falta dela - quanto à consideração da categoria gênero nas políticas educacionais afeta de maneira significativa a Educação Infantil. Desta maneira, serão apresentadas as indicações de desserviços que atingem os direitos das crianças pequenas e das mulheres, cujo reconhecimento e legitimidade sociais são desrespeitados abertamente, embora a não discriminação seja item há muito contemplado como instrumento assegurador dos direitos de cidadania, tanto na Educação quanto em outras esferas da sociedade.

\section{Gênero, mulheres, crianças e Educação: construções multifacetadas e relacionais}

Diante da defesa em favor do direito à Educação, é pertinente iniciar essa conversa justamente por essa questão no que se refere às meninas e mulheres. $\mathrm{O}$ acesso à Educação é reconhecido pelas abordagens que estudam gênero como o divisor de águas que possibilitou a participação efetiva das mulheres em relevantes esferas da vida em sociedade, como o acesso à universidade e ao mercado de trabalho. No Brasil, as 


\section{CIÊNCIAS HUMANAS}

REVISTA DO PROGRAMA DE PÓS-GRADUAĞ̈O EM EDUCAĞ̄o

\section{(1) URI|}

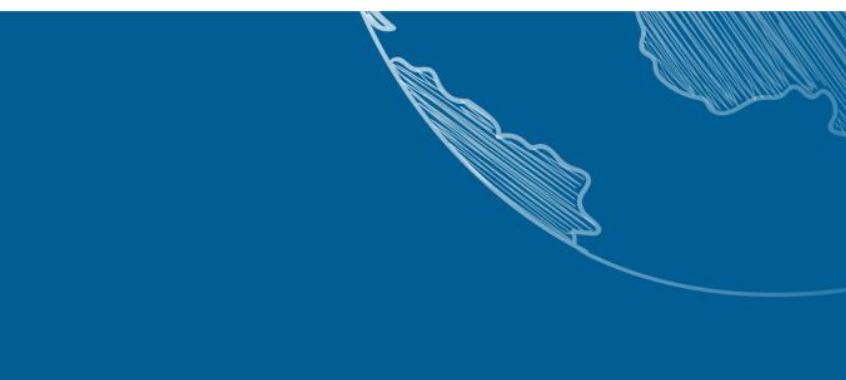

meninas tiveram o ingresso nas escolas primárias como direito reconhecido $\mathrm{e}$ assegurado em lei, no ano de 1827 (BRUSCHINI; AMADO, 1988 apud RABELLO; MARTINS, 2000). Embora a citada lei trouxesse em seu texto diferenciações curriculares que deveriam se aplicar à educação de meninos e meninas, estas últimas com limitações e direcionamentos aos afazeres domésticos, ressalta-se que, ao ocuparem os bancos escolares, as mulheres não somente ficaram a cargo de obter a instrução. Elas batalharam por outros lugares sociais, como a conquista de uma profissão e a luta e movimentação por seus direitos.

O ofício de professora significou uma ascensão para além do âmbito doméstico, embora o magistério estivesse sofrendo perda de prestígio diante do avanço do capitalismo industrial, como observa a autora Magda Chamon (2009). Esse advento agregou mais valor àquelas profissões ligadas à industrialização. Nessa direção, Marlette Schaffrath (2009) acrescenta ainda que o Estado Brasileiro passa a se preocupar com a capacitação docente em virtude dos processos de urbanização e concepções ligadas ao progresso da sociedade. Logo, a formação das crianças vira questão política, colocando a mulher como responsável direta tanto no meio familiar quanto no escolar, já que os homens foram sendo absorvidos por cargos de Estado, leiase, de maior peso e prestígio profissional (CHAMON, 2006).

Cabe aqui analisarmos os discursos que compõem um imaginário socialmente construído, percebido e criticado pelas estudiosas feministas. A experiência docente, assim como qualquer profissão ligada aos cuidados "[...] são admitidas como profissões femininas." (THURLER, 2009, p.5). Essa correspondência ocorre em virtude de uma divisão sexual do trabalho, que "[...] articula os campos de trabalho produtivo e reprodutivo [...] tanto excluindo quanto integrando as mulheres a esfera produtiva, devolvendo-as parcial ou totalmente à esfera reprodutiva" (DEVREUX, 2011, p 13). No Brasil, a professora Daniela Auad debate a tríade mãe-mulher-professora com base na naturalização da figura da professora a partir de entendimento de expectativas sociais que insistem em associar as figuras de mãe e de professora como sendo habilidades natas, puramente por se tratar de uma mulher (AUAD; RAMOS, 2015). Tais condições demonstram como os sistemas político e econômico estão permeados pelas relações de 


\section{CIÊNCIAS HUMANAS}

REVISTA DO PROGRAMA DE PÓS-GRADUAĞ̈O EM EDUCAĞ̄o

\section{(1) URI|"rismenco}

gênero em suas variadas dimensões, como bem definiu Joan Scott (1995, p.91). Para esta autora, amplamente apropriada por feministas e estudiosas de gênero no Brasil e em todo o mundo, gênero é "[...] uma fonte primária de dar significado às relações de poder". Como se sabe e aqui se menciona, uma complexa rede de processos históricopolíticos ocorreram e foram primordiais para que as mulheres traçassem uma trajetória rumo à sua independência, sinalizados na organização de movimentos sociais com especial militância por seus direitos e os de outros grupos, como as crianças. Um exemplo desse fenômeno é a luta por creche, tradicional bandeira de luta do movimento feminista, a qual, quando conquistada, assegura direitos tanto das mulheres quando das crianças.

Em termos de reconhecimento, muitos/as autores/as avaliam a diversidade de causas que contribuíram para a organização das instituições de Educação Infantil. Moisés Kuhlmann Junior (1998) nos aponta muitos desses fatores, tais como a participação das mulheres no mercado de trabalho, a urbanização, políticas assistencialistas e a influência de muitas áreas de conhecimento e de interesses. $\mathrm{O}$ cuidado e a proteção das crianças contavam com preocupações que correspondiam a um amplo leque temático, com questões relativas ao abandono tanto familiar quanto pela coletividade da sociedade, a ampliação dos currículos das Escolas Normais, a assistência à mulher grávida, a educação física, moral e intelectual, assim como a pediatria, higiene, entre outras. Assim sende Ademais, tais concepções constituintes da Educação Infantil acabaram por reforçar esse nível educacional como locus de cuidado e, assim sendo, com forte marca das representações de gênero tradicionais, binárias e centradas na heterossexualidade como norma e padrão de orientação sexual aceita e motivada. Desta maneira, os avanços em torno das especificidades da Educação Infantil se alinharam ao cuidado associado à figura da mulher, de modo a reforçar a tríade mãemulher-professora, mencionada anteriormente. A correspondência entre mulheres, cuidado e Educação Infantil se observa ampliada para além do trabalho parental, no interior das famílias e no âmbito daquilo que é conhecido como vida privada. A tríade mãe-mulher-professora se revela também em dados recentes obtidos no Ministério da Educação nos informam que as mulheres ocupam 97,9\% das vagas para professora/es 


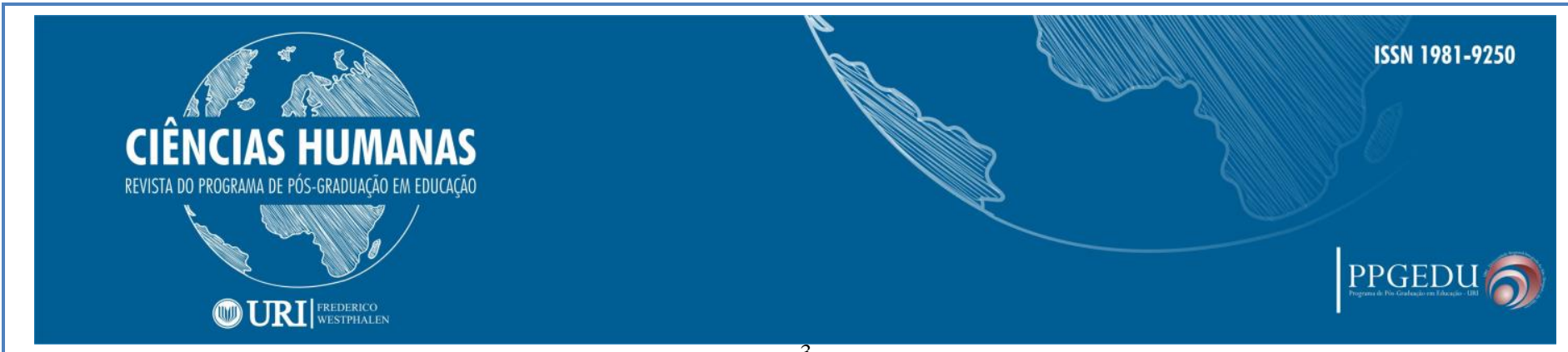

nas creches e escolas de Educação Infantil ${ }^{3}$. As mulheres também ocupam de forma massiva as funções de auxiliares das escolas. Deste modo, observamos que a hierarquização dos sexos se constitui como ato social, tanto nos espaços públicos quanto nos privados (TRONTO, 1997), como veremos a seguir.

\section{O silêncio repleto de significados dos documentos...}

[...] A questão de gênero - cujo tema principal visa combater duramente as práticas preconceituosas e discriminatórias iniciadas na infância - é o grande alvo de toda polêmica que envolve o Plano Nacional de Educação, já que obriga educadores a discutir com os alunos a equidade de gênero, seja qual for. O problema é que muitos religiosos protestam e defendem duramente a exclusão deste trecho que - para eles - é apenas um "detalhe" que contradiz sua moral. Infelizmente, o sistema de ensino brasileiro ainda cultua - mesmo que de forma inconsciente - toda uma carga de discriminação histórica que existe na sociedade contra as mulheres e - desta forma - o preconceito, desigualdade e machismo são reproduzidos (Bianchini,2015).

Esse é um fragmento de um texto ${ }^{4}$ da jornalista Alice Bianchini, que originou uma petição pública de reivindicação para que a proposta do Plano Nacional de Educação (PNE), votado no ano de 2014, mantivesse em suas orientações a abordagem do tema gênero no âmbito da Educação. A citação ilustra as disputas de setores civis em torno das disposições do texto legal do PNE, que vem se desenrolando há muitos anos, desde o PNE de 2001. Tais divergências também seguiram acirradas nas demandas de construção dos Planos Municipais de Educação em todo o país, e também no texto do Plano Municipal de Políticas para as Mulheres no município mineiro de Juiz de Fora. Existiram manifestações de setores religiosos que se posicionaram contrários a abordagem do tema gênero nos Planos, alegando a defesa da família, concebida de maneira conservadora, com respeito a uma única formação, composta pelo casal de

\footnotetext{
${ }^{3}$ Fonte: www.todospelaeducação.org.br Dado divulgado em 03/03/2011.

${ }^{4}$ Fonte: http://professoraalice.jusbrasil.com.br. Divulgado em 27/04/2015.
} 


\section{CIÊNCIAS HUMANAS}

REVISTA DO PROGRAMA DE PÓS-GRADUAĞ̈O EM EDUCAĞ̄o

\section{(1) URI|}

homem, mulher e a prole gerada de sua união. Reações que correspondiam a tensionamentos de retrocesso surgiram fortemente e incluíram o comprometimento público por parte de alguns vereadores em votar contra qualquer política pública que contemplasse questões relacionadas ao gênero, como foi amplamente divulgado pela imprensa local ${ }^{5}$.

O PNE de 2001 mencionava o tema gênero de maneira superficial e equivocada. Na apresentação do documento, os objetivos da Educação se comprometem a "[...] assegurar que até 2015 todas as crianças, particularmente meninas[...] tenham acesso à educação primária completa, gratuita, obrigatória e de boa qualidade[...] e alcançar igualdade de gênero na educação até 2015" (BRASIL, 2001, p. 17). Contudo, na seção destinada à Educação Infantil, o gênero é mencionado apenas na forma de estatísticas que apontavam a cobertura equilibrada de matrículas por sexo. No ano de 2010, a proposta de projeto substitutivo trouxe como uma de suas diretrizes a "superação das desigualdades educacionais, com ênfase na promoção da igualdade racial, regional, de gênero e de orientação sexual" (BRASIL, 2010, p.1-2). Já em 2014, essa diretriz suprimiu totalmente a menção ao gênero, substituindo os termos especificados nos projetos de 2010 por expressão genérica e vaga, “[...] com ênfase na promoção de cidadania e na erradicação de todas as formas de discriminação" (BRASIL, 2014, p.22), decisão recebida com muita indignação por vários movimentos sociais e associações de profissionais ligados à Educação.

Tal quadro, que culminou na omissão do tema gênero em 2014, já influenciava a movimentação de construção das propostas municipais ${ }^{6}$ da Educação Infantil, realizadas em 2010 e 2011. O primeiro documento - a proposta curricular intitulada Educação Infantil: A construção da prática cotidiana - faz referência ao tema, mas o desmerece, pois desconsidera que os materiais e artefatos possam permitir às crianças acessarem experiências "[...] independentemente de suas condições de gênero" (grifos

\footnotetext{
${ }^{5}$ Fonte: www.radiocatedraljf.com.br. Divulgado em 15/07/2015.

${ }^{6}$ As propostas curriculares da Educação Infantil de Juiz de Fora (MG) são duas : A prática cotidiana na EI: diálogos no cotidiano (2011) e Educação Infantil: A construção da prática cotidiana (2010).
} 


\section{CIÊNCIAS HUMANAS}

REVISTA DO PROGRAMA DE PÓS-GRADUAC̄̄o EM EDUCACĞ̄o

\section{(1) URI|}

das autoras, JUIZ DE FORA,2010, p.43). Diante dessa, lembramo-nos deinúmeros trabalhos que apontam que os brinquedos, por exemplo, atuam como fortes indicadores de posturas relacionadas ao gênero, seja para conservar padrões preconceituosos, seja para emancipar crianças e adultos de modelos tradicionais e binários.

Em estudos como os de Lílian Cruz, Zenilton Silva e Marcos Souza (2008), os brinquedos e brincadeiras são apontados como instrumentos utilizados a favor da educação do comportamento infantil, visto que o brincar se alinha com significados simbólicos ligados a modelos de feminilidade e masculinidade. A questão do brincar tem lugar de destaque nas produções acadêmicas de estudiosas de gênero que têm o olhar voltado à Educação Infantil, como as análises de Daniela Finco (2010), que assim como outras autoras, assevera que o brincar tem papel fundamental na produção de sentidos da criança pois este mobiliza uma série de dados simbólicos difundidos em sociedade, inclusive aqueles que direcionam as expectativas sobre o comportamento infantil, balizados pelas relações de gênero. Dito isto, a falta de aprofundamento sobre a questão sinalizada no primeiro documento curricular do município mineiro se estende no segundo, publicado em 2011, intitulado A prática cotidiana na EI: diálogos no cotidiano. Esse segundo documento curricular e norteador para a Educação Infantil se propõe a ser um caderno temático, trazendo sugestões de trabalho e temas mais específicos e não contem indicação alguma sobre trabalho com o gênero em suas orientações.

Essa omissão do tema na Educação Infantil no município de Juiz de Fora infelizmente vem acompanhando as tendências de silenciamento de outros Estados e Municípios brasileiros, conforme delineado desde o texto nacional e o que expressa que, parafraseando a antropóloga Cláudia Fonseca, o caso de Juiz de Fora não se trata de apenas um caso, mas se refere a uma realidade nacional na qual tensionamentos de retrocesso desejam interditar debates sobre gênero, raça, orientação sexual e outros temas considerados inadequados por setores ultraconservadores da sociedade.

Tais movimentações e pressões conservadoras e antidemocráticas se devem às manifestações propostas por entidades religiosas e que não necessariamente tem como base apenas a fé ou a crença espiritual. Trata-se de campo de conflito arraigado em 


\section{CIÊNCIAS HUMANAS}

REVISTA DO PROGRAMA DE PÓS-GRADUAĞ̈O EM EDUCAĞ̄o

\section{(1) URI|}

concepções que representam atentados à democracia, impactando diretamente as práticas escolares e as políticas educacionais e, quando aprovadas, se revelando excludentes e imparciais, desrespeitando os direitos de mulheres e meninas. Além disso, como aponta Ana Lúcia Goulart de Faria, trata-se de desmerecer “[...]o papel da infância na construção da realidade social" (FARIA, 2006, p.282), uma vez que também as infâncias são compostas por todos esses elementos que se deseja silenciar.

Como resultado desses processos, tem sido aviltados no ambiente escolar adolescentes LGBTs e crianças com composições familiares que coloquem lésbicas, gays, bissexuais e transgêneros, uma vez que têm sido veementemente censuradas " [...] a formulação de políticas públicas voltadas ao combate das desigualdades e à promoção de ações de integração e redução da evasão escolar da população LGBT”. Essa conjuntura que representa atentado à educação para a democracia é analisada pela pesquisadora Jasmine Moreira, em sua pela dissertação, cujo título é Janelas Fechadas: a questão LGBT no PNE 2014 (2016). Essa produção e tantas outras indicam que há debate e formação de acúmulo contínuo e que considera a categoria gênero acerca de todos os níveis e modalidades de ensino. Vejamos, então, o que as fontes teóricas veiculadas pelo MEC indicam sobre a abordagem do gênero.

\section{Gênero e Educação Infantil: um estudo da bibliografia disponível}

Existem materiais disponíveis no site do MEC voltados à formação/atualização de professoras/es. Nesse universo, selecionamos materiais relativos à Educação Infantil, e também a seção Estudos e Pesquisas. Foram selecionados onze textos que remetiam a diversas questões pedagógicas a serem abordadas junto às crianças pequenas, como o conhecimento matemático, as ações voltadas aos bebês, avaliação, brinquedos, relações com a natureza, linguagem escrita, currículo, Educação Infantil no campo, relações interpessoais, saúde e gênero. Os trabalhos foram analisados à luz da categoria gênero e as variadas percepções das autoras dos textos selecionados sobre ao que se refere abordar gênero, seja como categoria, temática e/ou campo de questionamento. Concluímos que seis textos mencionam explicitamente a abordagem do tema gênero na 


\section{CIÊNCIAS HUMANAS}

REVISTA DO PROGRAMA DE PÓS-GRADUAĞ̈O EM EDUCAĞ̄o

\section{(10)URI|}

Educação Infantil. O texto que aborda a avaliação não faz alusão ao tema. Curiosamente, os quatro trabalhos restantes não mencionam relações de gênero, embora a categoria se faça presente nos campos discutidos pelas autoras. Para ilustração dessa assertiva, o texto que considera as crianças como 'seres da natureza nas múltiplas dimensões de interação', relaciona as práticas da sustentabilidade somente ao meio natural. Tal afirmação não dialoga, por exemplo, com as proposições da feminista Sondra Farganis (1997), que além de localizar a divisão da sociedade pelo gênero, pondera que uma relação de parceria com a natureza afeta diretamente " [...] a maneira com que abordamos as realidades físicas e sociais" (FARGANIS,1997, p.228, grifo nosso). Essa invisibilização é discutida pela pesquisadora Nancy Fraser (2007), que discorre sobre a dificuldade de reconhecimento por parte da comunidade acadêmica. Para ela, pesquisadores/as “[...] que entendem gênero como uma relação social mantêm uma difícil coexistência com aqueles que o constroem como uma identidade ou um código cultural" (FRASER, 2007, p.102). Logo, a percepção quanto à amplitude de atuação e de adoção (com vistas à transformação) da categoria gênero fica prejudicada (RAMOS,2016) e sequer acessa o nível analítico e de diferenciação da adoção da categoria gênero contido na proposta epistemológica de Nanci Fraser.

Já a seção Estudos e Pesquisas conta com significativo estudo do pesquisador Edilberto Sastre, intitulado "Panorama dos estudos sobre violência nas escolas no Brasil; 1980 - 2009”. O trabalho é emblemático e revelador com relação à magnitude da expressão das relações de gênero, raça e orientação sexual no ambiente escolar, tanto em diagnosticar suas manifestações quanto em apontar a potência da abertura dos espaços escolares para o debate. Em cenário de tanta desconsideração de gênero como categoria, como tema ou como identidade, o autor desponta em abordagens que abrangem alunas e alunos, docentes e familiares, na perspectiva de processos de gestão democrática.

Considerando as fontes teóricas analisadas, é possível vislumbrar não apenas a(s) maneira(s) com que a categoria pesquisada aparece na escola, mas também algumas possibilidades de ação que enfrentem a banalização de práticas que oprimam ou invisibilizam alguns grupos sociais, a saber as discriminações baseadas nas relações de 


\section{CIÊNCIAS HUMANAS}

REVISTA DO PROGRAMA DE PÓS-GRADUAĞ̈O EM EDUCAĞ̄o

\section{(1) URI|}

gênero tradicionais. Dito isso, o próximo passo foi apurar como essas assertivas são pensadas por pessoas que atuam junto à diversas esferas educativas na cidade de Juiz de Fora (MG).

\section{Em conversa com o campo, a construção de um diálogo...}

O campo acessado pela pesquisa foi delineado a partir de mapeamento da rede de práticas educativas que afetam as crianças, no que se refere às relações de gênero. Foi questionado e analisado como as relações de gênero são repetidas e/ou questionadas e/ou reformuladas tanto na escola quanto fora dela. As análises se pautaram na produção bibliográfica acessada, em trabalhos de pesquisadoras estudiosas de gênero e feministas e em estudos da Educação Infantil que pesquisam esse nível de ensino sob o viés do gênero. Foram realizadas entrevistas junto ao setor de Educação Infantil da Secretaria Municipal de Educação, com professoras de uma escola da rede municipal e com representante da Coordenadoria de Políticas Públicas Casa da Mulher, com o intuito de conhecer a opinião das entrevistadas sobre o trato das questões de gênero junto às crianças.

As entrevistadas reconhecem a relevância do trato das questões de gênero junto às crianças, sustentando argumentos diferentes a esse respeito. Foi entrevistada a coordenadora da Casa da Mulher de Juiz de Fora, importante instituição municipal de referência da igualdade de gênero e enfrentamento à violência contra a mulher. E vale aqui destacar o quão rara e escassa podem ser políticas igualitárias, em todas as pastas governamentais, em uma cidade com 600 mil habitantes. A entrevistada em questão situa a importância desse debate nos direitos da mulher, visibilizando principalmente o combate à violência doméstica. As representantes da Secretaria de Educação e as professoras destacam o princípio do respeito e da diversidade humana, que perpassa a relação com as famílias e as brincadeiras. Quando questionadas especificamente sobre o que "diversidade" significa, as entrevistadas da Secretaria de Educação associam a gênero e à orientação sexual, e também conflitos relativos ao preconceito racial, ressaltando o papel das práticas educativas voltadas às citadas relações. A representante 


\section{CIÊNCIAS HUMANAS}

REVISTA DO PROGRAMA DE PÓS-GRADUAĞ̈O EM EDUCAĞ̄o

\section{(1) URI|}

da Casa da Mulher acrescenta a importância do poder público em garantir, ao debater gênero na escola, a manutenção da qualidade das relações integrais e amplas, inclusive no campo educacional. Outros pontos de destaque das entrevistadas remetem à críticas de valorização de temas sociais somente em datas comemorativas, a preocupação com a seleção do teor de obras literárias como material de apoio à abordagem do gênero, a construção autônoma por parte das crianças e os momentos de formação continuada oferecidos pela Secretaria.

Apesar das considerações das profissionais da Secretaria de Educação apontarem dados positivos a partir de suas falas, foi apurado em pesquisa que a oferta de cursos voltados especificamente ao tema gênero foi interrompida pela citada pasta do Governo Municipal, ainda que o tema seja recorrente no cotidiano escolar e com iniciativas frequentes da $\mathrm{UFJF}^{7}$ em ofertar cursos, disciplinas, eventos de extensão e atividades que abordem as relações de gênero junto às professoras/es das redes de ensino, tanto a municipal, quanto estadual, assim como as das escolas privadas. Outro ponto contraditório das entrevistas foi o questionamento do porquê da superficialidade e do silenciamento da abordagem do gênero nas propostas curriculares de 2010 e de 2011. A Secretaria, ao ter sua representante entrevistada, informou que o documento foi uma construção que foi ganhando robustez ao longo de vários momentos de discussão entre a comunidade escolar e acadêmica, de modo a não contemplar todos os temas de uma só vez. Cumpre destacar que, ainda que se desenrole tal processo de construção contínua, também nos foi informado que o documento não será atualizado à luz de novas discussões acerca das relações de gênero, o que constitui flagrante contradição nas entrevistas. Tal situação é grave no que concerne à democracia e à proteção de crianças e adolescentes quanto à, por exemplo situações de violência sexual e doméstica. As propostas curriculares do município são referências de trabalho pedagógico a serem seguidas por toda a rede. Ao lado disso, a representante da Casa da Mulher de Juiz de Fora, ao ser perguntada sobre a existência de alguma parceria desse equipamento municipal com as escolas, nos informou que procurou a Secretaria de Educação para

\footnotetext{
${ }^{7}$ Universidade Federal de Juiz de Fora (MG).
} 


\section{CIÊNCIAS HUMANAS}

REVISTA DO PROGRAMA DE PÓS-GRADUAĞ̈O EM EDUCAĞ̄o

\section{(1) URI|}

propor formação continuada sobre a questão do combate à violência de gênero mas não foi atendida em seu propósito.

As entrevistas revelaram ainda que as professoras de Educação Infantil vão trabalhando do jeito que podem, das maneiras que pensam entender como corretas e, ao relatarem suas práticas, demonstram insegurança em suas intervenções. Tal sensação se deve, segundo elas, pelas inconsistências do que ensinar e como abordar as questões de gênero, orientação sexual, assim como variados modelos de família. Esses conteúdos e debates não foram, na maioria dos casos, objeto da formação inicial dessas docentes e, como era de se esperar, tais temáticas perpassam suas condições de trabalho, seu cotidiano docente e suas vidas em variadas esferas para além da profissional, afetando suas construções de mundo e outras identidades que não apenas a docente. Assim, no município mineiro que se avizinha ao Rio de Janeiro, os documentos norteadores da Educação da municipalidade omitem o tema gênero e isso foi até mesmo objeto de votação pelos vereadores, com enfática negação do uso do termo gênero mas com a admissão do uso do termo diversidade para se referir às pessoas com deficiência e com superdotação. Esse fenômeno é expressivo do uso do termo diversidade como slogan para negar e apagar temas que são foco de preconceito e que são silenciados em razão de machismo, lesbo/homo/trans/bifobia institucionais e racismo, além de arraigado preconceito de classe.

Com esses dados coletados de modo intenso e aprofundado, é possível notar como que, na cidade de Juiz de Fora, apesar dos debates acalorados pela manutenção do termo gênero, a interdição desse debate na escola seguiu a tendência de retrocesso de muitas localidades no Brasil. A pesquisa que o presente texto noticia é uma das expressões de resistência feminista na cidade, no Estado, em território nacional. Nossa escrita demarca e registra que há estudiosas, militantes, pesquisadoras e docentes espalhadas nas escolas, universidades e equipamentos governamentais, ali, onde estivermos, se preza pelo debate e pela transformação das relações de poder. 


\section{CIÊNCIAS HUMANAS}

REVISTA DO PROGRAMA DE PÓS-GRADUAC̄̄o EM EDUCACĞ̄o

\section{(1) URI|}

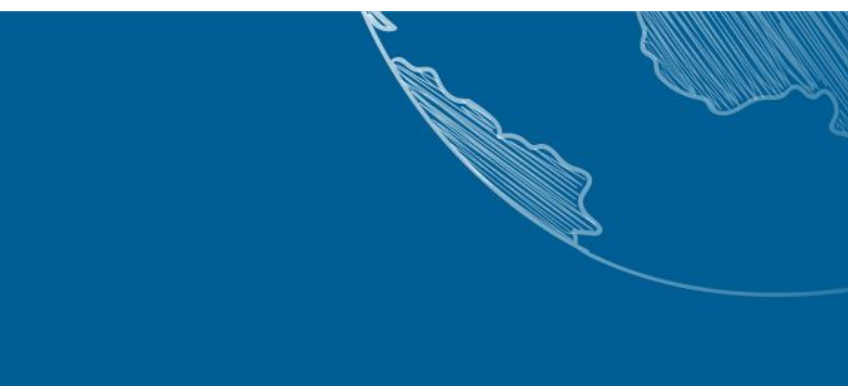

\section{Gênero e Educação como linha de Política Pública Educacional Igualitária}

A realização da pesquisa que esse texto informa e noticia não se fez tanto a partir de um movimento de encontrar respostas para hipóteses pré-estabelecidas. Fomos à campo perguntar e acessamos bibliografias para comparar e analisar cenários e respostas, de modo a colocar em diálogo nossos achados localizados com realidades outras e além de onde nossa mão e visão alcançavam. Esse movimento tornou nossa pesquisa mobilizadora de reflexões, aprendizados e esforços tanto das pesquisadoras quanto das entrevistadas, no sentido de pensar ações educativas com objetivos que se colocassem a favor de medidas educacionais igualitárias a serem acessadas pelas crianças na Educação Infantil.

Eleger gênero como categoria de análise se mostrou uma boa via de promoção de experiências que se coadunam com nossos melhores desejos de democracia, ao mesmo tempo que entendemos e defendemos a escola, por excelência, como um espaço para além da produção de conhecimento, mas também para a multiplicação na comunidade e nas famílias de subjetividades que não sejam cristalizadas e arraigadas em binarismos.

Entendemos a escola como espaço de acolhimento por excelência, sobretudo na Educação Infantil, onde o cuidar se coloca a flor da pele nos tempos e espaços. Isso torna fundamentais os princípios de apreço e de respeito por todas as formações familiares, pelas múltiplas identidades de gênero e pela pluralidade das orientações sexuais e raças-etnias. A Educação Infantil é campo fértil para a motivação dessas relações, considerando a centralidade da criança e a potencialidade do convívio na escola. Colocar a criança no centro das relações e apostar na consideração da multiplicidade das categorias pode ser movimento gerador de novas e potentes relações pela via da socialização escolar.

Tecidas as nossas considerações ao longo do texto, vale ressaltar que os pontos aqui debatidos podem ser levados em consideração tanto quando da discussão dos problemas que afetam as infâncias no município de Juiz de Fora quanto em outras localidades do Brasil, já que a interdição do debate sobre gênero no campo da Educação 


\section{CIÊNCIAS HUMANAS}

REVISTA DO PROGRAMA DE PÓS-GRADUAĞ̈O EM EDUCAĞ̄o

\section{(1) URI|}

significa um retrocesso nacional nos direitos das crianças como cidadãs brasileiras. Estas têm seus direitos desrespeitados quando se retira da Educação todo e qualquer debate que amplie suas vivências para além do universo que coloca como centro o homem, branco, heterossexual, cristão, apegado a valores das classes que se desejam dominantes e que estão situadas em grandes centros urbanos.

A pretensão de interdição do diálogo sobre gênero, ao limitar a construção de repertório na infância e ao limitar os debates na escola, nos faz deparar com flagrantes tentativas de recuperar perspectivas descoladas da realidade e incapacitantes sobre as crianças, como se a infância ou a velhice fossem lugares dos incapazes por excelência. Vale notar que diferente dessa mentalidade, as crianças são cidadãs ativas e de direitos, como já estabelecido na Constituição Federal de 1988, no Estatuto da Criança e do Adolescente e na própria Lei de Diretrizes e Bases da Educação Nacional.

Tal conjuntura indica que os esforços empreendidos na luta pelos Direitos das Crianças e dos Adolescentes precisam se consolidar mais e a cada dia, uma vez que seguem emparelhados - pois continuamente ameaçados - com os Direitos das Mulheres e da População LGBT. Essa intersecção de populações em condição de vulnerabilidade nos mostra, dentre muitos elementos, que a interdição em torno do debate de gênero vai muito além da desconsideração das crianças enquanto cidadãs, o que já seria ruim o suficiente, mas se refere a uma perversa maneira de atentar contra o Estado Democrático de Direito, o que não podemos em tempo algum permitir.

\section{REFERÊNCIAS}

AUAD, Daniela. RAMOS, Maria R. Relações de Gênero e Docência na Educação Infantil: interfaces entre políticas públicas e abordagens pedagógicas.In: SEMINÁRIO ENLAÇANDO SEXUALIDADES 2015. Anais IV Seminário Enlaçando Sexualidades 2015. Disponível em www.uneb.br/enlacandosexualidade/2015/ 07/08/anais-IV-seminario-enlacando-sexualidade-2015/

BRASIL. Lei no 13.005, de 25/06/2014. Aprova o Plano Nacional de Educação (PNE) e dá outras providências. Câmara dos Deputados. Brasília; Edições Câmara, 2014.

Plano Nacional de Educação. Senado Federal. Brasília; 2001, 186 p. 


\section{CIÊNCIAS HUMANAS}

REVISTA DO PROGRAMA DE PÓS-GRADUAĞ̈O EM EDUCAĢĀO

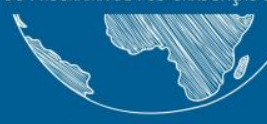

(10)URI| |rRDERco

Projeto de Lei no 13.005. Dispõe sobre o Plano Nacional de Educação.

Disponível em www.planalto.gov.br/ccivil_03/_ato2011-2014/lei/113005.htm Acesso em $24 / 10 / 2014$.

CHAMON, Magda. Trajetória de feminização do magistério e a (com)formação das identidades profissionais. VI Seminário da Redestrado - Regulação Educacional e Trabalho Docente. 06 e 07 de novembro de 2006-UERJ-Rio de Janeiro-RJ - P.1-16. Disponível em -- Acesso em 29/07/2014.

CRUZ, Lilian M. SILVA, Zenilton G. SOUZA, Marcos L. O brinquedo e a produção do gênero na educação infantil: uma análise pós-estruturalista. Disponível em www.periodicos.ufes.br/gepss/article/download/3880/3095 Acesso em 29/03/2013.

DEVREUX, Anne-Marie. A teoria das relações sociais de sexo: um quadro de análise sobre a dominação masculina. In: Cadernos de Crítica Feminista. 2011, ano V, n.4, P. 06-29.

FARIA, Ana Lúcia Goulart de. Pequena infância, educação e gênero: subsídios para um estado da arte. Cad. Pagu, Campinas, n. 26, p. 279-287, jun. 2006 . Disponível em http://www.scielo.br/scielo.php?script=sci_arttext\&pid=S010483332006000100012\&ln $\mathrm{g}=\mathrm{pt} \& \mathrm{nrm}=$ iso Acesso em 08/05/2018.

FARGANIS, Sondra. O feminismo e a reconstrução da ciência social. In: JAGGAR, Alison M.; BORDO, Susan R. Gênero, Corpo, Conhecimento. Rio de Janeiro, Record, Rosa dos Tempos, 1997

FINCO, Daniela. Educação infantil, espaços de confronto e convívio com as diferenças: análise das interações entre professoras e meninas e meninos que transgridem as fronteiras de gênero. São Paulo, 2010. Tese de Doutorado. (Programa de Pós Graduação em Educação) Faculdade de Educação da Universidade de São Paulo. Disponível em www.teses.usp.br/teses/disponiveis/48/48134/tde20042010.../DANIELA_FINCO.pdf Acesso em 07/05/2018.

FONSECA, Claudia. Quando cada caso NÃO é um caso: pesquisa etnográfica e educação. Revista Brasileira de Educação, Rio de Janeiro, ANPEd, n. 10, p. 58-78, jan./abr. 1999.Disponível em www.anped.org.br/sites/default/files/rbe/files/rbe_10.pdf Acesso em 06/05/2018

FRASER, Nancy. Reconhecimento sem ética? Lua Nova, São Paulo, 2007 - P. 101138.

JUIZ DE FORA, Secretaria de Educação. A prática cotidiana na EI: diálogos no cotidiano. Contempla os fundamentos teóricos e a organização prática das instituições de Educação Infantil em Juiz de Fora. 2011.62p. 


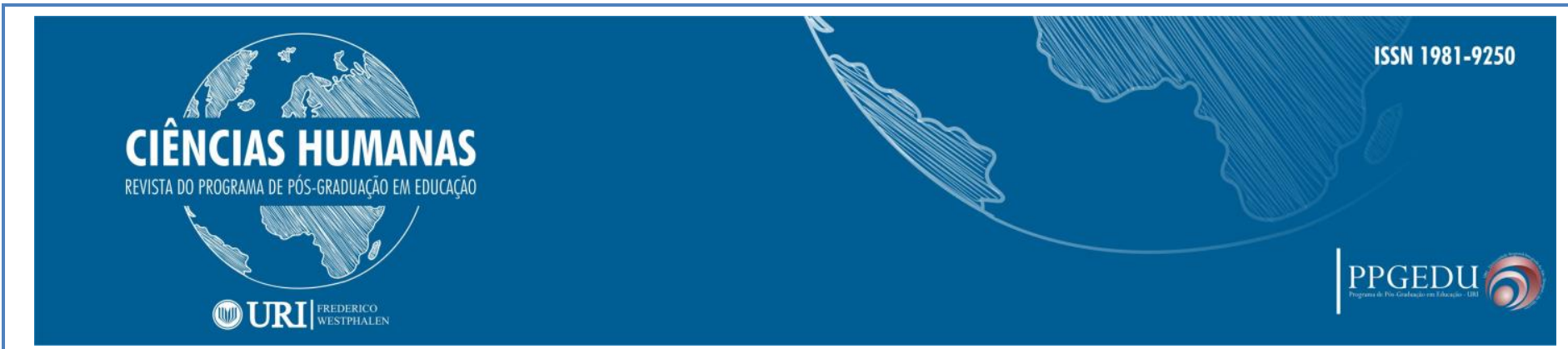

. Secretaria de Educação. Educação Infantil: A construção da prática cotidiana.

Trata dos princípios que devem orientar a organização das instituições de Educação Infantil em Juiz de Fora. 2010. 61 p.

KUHLMANN JUNIOR, Moysés. Infância e Educação Infantil: uma abordagem histórica. Porto Alegre; Mediação, 1988.

MARTINS, Antonio Ribeiro; RABELO, Amanda Oliveira. A mulher no magistério brasileiro: um histórico sobre a feminização do magistério. Disponível em Pe://www2.faced.ufu.br/colubhe06/anais/arquivos/556AmandaO.Rabelo.pdf Acesso em 19/07/2014.

MOREIRA, Jasmine. Janelas Fechadas: a questão LGBT no PNE 2014. Curitiba, 2016. Dissertação (Programa de Pós Graduação em Educação) Universidade Federal do Paraná.

RAMOS, Maria Rita Neves. Relações de gênero e docência na Educação Infantil: interfaces entre políticas públicas e abordagens pedagógicas. Juiz de Fora, 2016. Dissertação (Programa de Pós Graduação em Educação) Universidade Federal de Juiz de Fora.

SCOTT, Joan Wallach. Gênero: uma categoria útil de análise histórica. Educação \& Realidade. Porto Alegre, vol.20, $\mathrm{n}^{\circ}$ 2, jul/dez.1995, P.77-99.

SCHAFFRATH, Marlete dos Anjos Silva. Escola Normal: O projeto das elites brasileiras para a formação de professores - P.142-152. Disponível em http://www.fap.pr.gov.br/arquivos/File/Arquivos2009/Extensao/I_encontro_inter_artes/ 20_Marlete_Schaffrath.pdf Acesso em 26/07/2014

THURLER, Ana L. Primeira infância no Brasil do século XXI: desafios ao reconhecimento institucional. In: BASTOS, Eliene F. Assis, Arnoldo C. SANTOS, Marlouve M. S. Família e Jurisdição III. Belo Horizonte: Ed. Del Rey. 2009.p.1- 34.

TRONTO, Joan C. Mulheres e cuidados: o que as feministas podem aprender sobre a moralidade a partir disso? In: JAGGAR, Alison M.; BORDO, Susan R. Gênero, Corpo, Conhecimento. Rio de Janeiro, Record, Rosa dos Tempos, 1997. 